\title{
Good Practices in Finite Element Method with a Frequency Analysis Exam- ple
}

\section{Dr. Luis E. Monterrubio, Robert Morris University}

Luis Monterrubio joined the Robert Morris University Engineering Department as an Assistant Professor in the Fall of 2013. He earned his B.Eng. from the Universidad Nacional Autónoma de México, his M.A.Sc. from the University of Victoria, Canada, and his Ph.D. from the University of Waikato, New Zealand. All degrees are in Mechanical Engineering and both M.A.Sc. and Ph.D. studies are related with vibrations. After his Ph.D. he worked at the University of California, San Diego as postdoctoral fellow in the area of bioacoustics. He teaches dynamics, machine design, numerical methods and finite element methods. He has work for the automotive industry in drafting, manufacturing, testing (internal combustion engines-power, torque and exhaust emissions, vibration fatigue, thermo-shock, tensile tests, etc.), simulations (finite element method), and as a project manager (planning and installation of new testing facilities). 


\section{Good Practices in Finite Element Method with a Frequency Analysis Example}

\section{Introduction}

The finite element method (FEM) allows engineers to solve different types of problems (solid mechanics, heat transfer, vibration, electromagnetic, acoustic, etc.) and it is often included in the curricula of undergrad engineering programs. This method consists of discretizing a continuum into smaller elements which properties are defined in matrix form. Then, the element matrices are used to assemble the global matrices representing the properties of the whole structure.

Frequency analysis is a very relevant topic during the design of new products and it is usually carried out during the design of any component of a structure subjected to dynamic loads. Even though resonance problems have been known for a long time, this problem continues to appear in many structures such as in the London Millennium Bridge in the U.K. in year 2000.

Although other works have been presented at previous ASEE Conferences related with natural frequencies either calculated with a Matlab code, testing or using FEM including [1-3] the present work presents all three alternatives and the main difference with previous publications is that the objective of this work is to pinpoint good practices using commercial finite element codes. The good practices in the implementation of a finite element analysis (FEA) presented in this work are:

a) Have a good understanding of the theory related to the problem to be solved. For this reason the solution of a cantilever beam is presented in this work in order to have an example whose analytical solution can be easily obtained. This is achieved solving for natural frequencies and modes of vibration using the Rayleigh-Ritz method.

b) Have a good understanding of the basics of the FEM. This is achieved solving for natural frequencies and modes of vibration implementing a FEM code in Matlab [4].

c) Have experience with the different types of elements that can be used in the analysis. This is achieved using linear and non-linear beam, shell and solid elements in the finite element code Abaqus [5] or other commercial FEM code.

d) Have experience checking the convergence of the results with respect to the degrees of freedom included in the solution. This is achieved defining coarse meshes in the first analyses with a particular element type and refining the mesh until convergence of the results is observed.

e) Have the ability to compare FEA results with analytical and/or experimental tests. This is achieved using results using the Rayleigh-Ritz method obtained in a) and experimental results obtained using an impact hammer and an accelerometer mounted on the structure

After the activities mentioned above, students will be familiar with the finite element theory and the solution of the generalized eigenvalue problem used to obtain the natural frequencies and modes of vibration of a structure. 
Written reports are used to assess students' work. The content of the reports include the type of element used, the number of degrees of freedom in the solution and how the FEA results converge as the number of degrees of freedom increases. Students must also compare their FEA results using a commercial code with the other types of solutions mentioned earlier (RayleighRitz method, implemented FEM code in Matlab and experimental work). ABET [6] outcomes a, $\mathrm{b}, \mathrm{g}$, and $\mathrm{k}$ are assessed.

Results show that students enjoy working with commercial FEM codes and experimental work. This is shown with clearly higher lab reports' grades -usually higher than $90 \%$, while the average of exams' grades were around $75 \%$ with a standard deviation around $15 \%$.

\section{Content of the proposed set of labs}

As an introduction to the basic concepts of vibration and the generalized eigenproblem for a twodegree-of-freedom-system is solved in class. The system in this example consists of two springs and two masses. Then, solutions of a cantilever beam using different approaches are implemented.

Natural frequencies and modes of vibration are obtained from the solution of the generalized eigenvalue problem defined in equation (1)

$$
[K]\{x\}-\omega^{2}[M]\{x\}=\{0\}
$$

where $[K]$ is the stiffness matrix of the beam, $[M]$ is the mass matrix of the beam, $\{0\}$ is the null vector, while $\omega^{2}$ and $\{x\}$ are the eigenvalues and eigenvectors. Note that the square roots of the eigenvalues give the circular natural frequencies of the beam in radians per second, while the eigenvectors give the modes of vibration of the beam.

Thus, procedures presented in 1.1, 1.2 and 1.3 consist in different ways to compute the stiffness matrix of a beam $[K]$, the mass matrix of a beam $[M]$ and then solve the generalized eigenvalue problem given above to obtain the natural frequencies and modes of vibration of the beam.

Basic information about beam theory is presented before these labs. Students must be able to compute the finite element stiffness matrix and mass matrix of beam elements using the Rayleigh-Ritz method (or Galerkin method) from scratch deriving the shape functions as well. In addition, basic concepts related with accelerometers and Fast Fourier Transformation (FFT) is presented with the labs.

\subsection{Rayleigh-Ritz method}

The RRM is an energy method that consists of carrying out a minimization (partial derivatives with respect to the unknown coefficients) of the energy terms involved in the problem. In this case, the Rayleigh-Ritz minimization gives the stiffness matrix and the mass matrix of the beam. To allow flexibility in the type of problems given to students, the set of admissible function used in the RRM models an unconstrained beam and all constraints are modelled by translational and rotational springs with a very high stiffness. For instance, Figure 1 shows a beam with

translational and rotational springs at both ends to model a clamped-clamped beam. In addition it is possible to add masses at any point along the beam to investigate the change of the natural 
frequencies due to inertial changes. The Matlab code to obtain results using thie Rayleigh-Ritz method is given in the Appendix.



Figure 1. Beam of length $\mathrm{L}$ with translational springs $k t$ and rotational springs $k r$

The strain energy of the beam is defined as [7]:

$$
V_{\text {beam }}=\frac{E I}{2} \int_{0}^{L}\left(\frac{\partial^{2} W(x)}{\partial x^{2}}\right)^{2},
$$

where $E I$ is the flexural rigidity of the beam. The strain energy of each translational spring $k_{t}$ and rotational spring $k_{r}$ used to modeled constraints at an arbitrary point $x=x_{\text {spring }}$ is defined as [7]:

$$
V_{\text {spring }}=\left.\frac{k_{t}}{2}(W(x))^{2}\right|_{x=x_{\text {spring }}}+\left.\frac{k_{r}}{2}\left(\frac{\partial W(x)}{\partial x}\right)^{2}\right|_{x=x_{\text {spring }}}
$$

The kinetic energy of the beam is defined as [7]:

$$
T_{\text {beam }}=\frac{\omega^{2} \rho A}{2} \int_{0}^{L} W(x)^{2} d x
$$

where $\rho$ is the density of the material, $A$ is the cross-sectional area of the beam. The kinetic energy of additional masses (and inertia) added at an arbitrary point $x=x_{\text {mass }}$ to the beam is defined as [7]:

$$
T_{\text {mass }}=\left.\frac{\omega^{2} m_{p}}{2}(W(x))^{2}\right|_{x=x_{\text {mass }}}+\left.\frac{\omega^{2} I_{p}}{2}\left(\frac{\partial W(x)}{\partial x}\right)^{2}\right|_{x=x_{\text {mass }}}
$$


where $m_{p}$ and $I_{p}$ are the mass and inertia properties added to the beam at $x=x_{\text {mass }}$, while $W(x)$ is the deflection shape of the neutral line of the beam that can be expressed in terms of the set of admissible functions as

$$
W(x)=\sum_{i=1}^{n} a_{i} \varphi_{i}(x)
$$

where $a_{i}$ are arbitrary coefficients and $\varphi_{i}(x)$ represent the set of admissible functions that in the classical Rayleigh-Ritz method satisfy the boundary conditions defined in equation (7)

$$
\begin{gathered}
\varphi_{1}(x)=1 \\
\varphi_{2}(x)=x / L \\
\varphi_{3}(x)=(x / L)^{2} \\
\varphi_{i}(x)=\cos (i-3) \pi(x / L) \text { for } i=1,2,3, \ldots \text { to } n,
\end{gathered}
$$

where $n$ is the number of terms used in the set of admissible functions.

The minimization of the strain energy gives the terms of the stiffness matrix defined as:

$$
\begin{gathered}
K_{i, j}=E I \int_{0}^{L} \varphi_{i}^{\prime \prime}(x) \varphi_{j}^{\prime \prime}(x) d x \\
+k_{t} \varphi_{i}\left(x=x_{\text {spring }}\right) \varphi_{j}\left(x=x_{\text {spring }}\right)+k_{r} \varphi_{i}^{\prime}\left(x=x_{\text {spring }}\right) \varphi_{j}^{\prime}\left(x=x_{\text {spring }}\right),
\end{gathered}
$$

where the prime and double prime indicate the first and second derivatives with respect to $\mathrm{x}$, respectively. The terms of the mass matrix are defined by

$$
\begin{gathered}
M_{i, j}=\rho A L \int_{0}^{L} \varphi_{i}(x) \varphi_{j}(x) d x \\
+m_{p} \varphi_{i}\left(x=x_{\text {mass }}\right) \varphi_{j}\left(x=x_{\text {mass }}\right)+I_{p} \varphi_{i}^{\prime}\left(x=x_{\text {mass }}\right) \varphi_{j}^{\prime}\left(x=x_{\text {mass }}\right)
\end{gathered}
$$

The modes of vibration can be calculated from the generalized eigenvalue problem defined in equation (1). The eigenvalues are the square of the circular natural frequencies, while the eigenvectors give the unknown coefficients of the deflection shape of the neutral axis. The modes of vibration can be now calculated using

$$
\Psi(x)=\sum_{i=1}^{n} a_{i} \varphi_{i}(x)
$$

\subsection{FEM using Matlab}

Students have to write a Matlab code that builds the stiffness and mass matrix of an unconstrained beam using a desired amount of elements. Students have to apply boundary conditions and solve the eigenproblem. Natural frequencies are computed getting the square roots of the eigenvalues, while modes of vibration can be plotted gathering only translational values of the eigenvectors.

It must be clear that bending can take place in two directions. Thus, the analysis using Matlab codes (RRM and FEM) must be run twice. Once per bending direction and its corresponding 
second moment of area $I$. Finite element analyses (FEA) in Abaqus include six degrees of freedom at each node. Thus, in addition to the natural frequencies with bending modes in two directions results obtained using Abaqus include torsional and longitudinal modes, which aren't computed in the Matlab codes (RRM and FEM).

\subsection{FEM using Abaqus}

The general procedure to set up a frequency analysis in Abaqus is

a) Define geometry

b) Define material

c) Define section and profile

d) Assign section and beam orientation

e) Create instance, seed instance and mesh with element

a. Beam (linear and quadratic elements)

b. Shell (linear and quadratic elements)

c. Solid (linear and quadratic elements)

Students are encouraged to use only a few elements every time they use a different element type and refine the mesh to observe the convergence of the analysis with respect to the number of degrees of freedom included in the analysis.

f) Create frequency step

g) Apply boundary conditions

h) Submit the job

i) Post-process

\subsection{Experimental work}

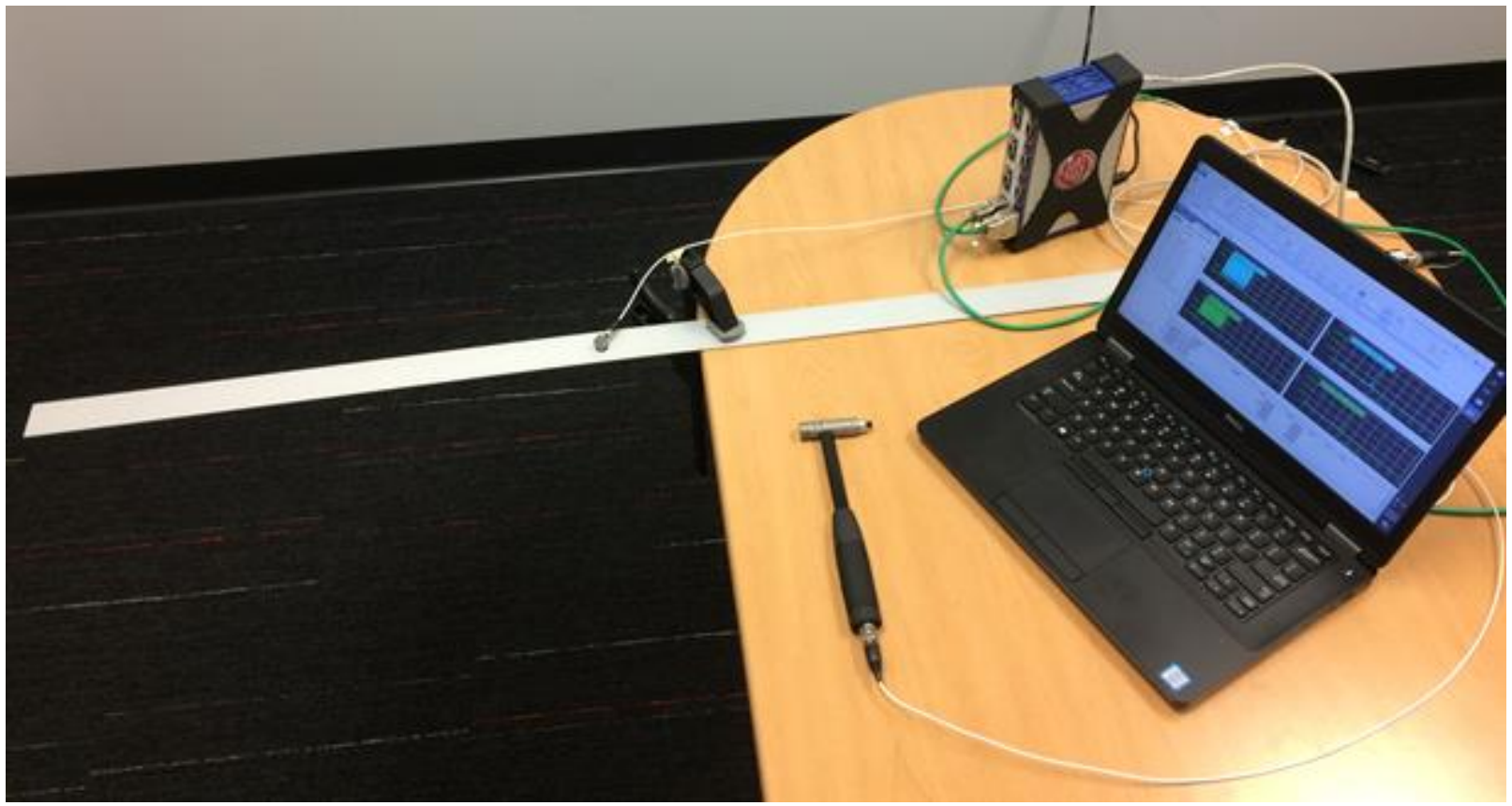

Figure 2. Experimental test set up. 
Natural frequencies were measured using a impact hammer and an accelerometer. The set up of the experimental work is in Figure 2. A modal hammer and an accelerometer mounted on the beam were connected to a Quantum X (HBM) DAQ and the output was visualized on a laptop with catman (HBM) software and Matlab installed. Fast Fourier Transformation was applied to the ratio between the output (accelerometer) and the input (impact hammer) to determine the natural frequencies of the beam.

\section{Results}

First tables to investigate the convergence of the results as the number of DOF in the system increases must be created. Then students must complete the table below recording the first six natural frequencies and make a plot of the first natural frequencies in the Matlab approaches. Students must use these plots to identify the equivalent results obtained in Abaqus. Experimental results are also included in Table 1.

Comparison of natural frequencies obtained using all methods are shown in Table 1.

\begin{tabular}{|c|c|c|c|c|c|c|}
\hline Method & $\begin{array}{l}\text { RRM } \\
\text { Matlab }\end{array}$ & $\begin{array}{l}\text { FEM } \\
\text { Matlab }\end{array}$ & $\begin{array}{l}\text { Abaqus } \\
\text { Beam } \\
\text { Element }\end{array}$ & $\begin{array}{l}\text { Abaqus } \\
\text { Beam } \\
\text { Element }\end{array}$ & $\begin{array}{l}\text { Abaqus } \\
\text { Beam } \\
\text { Element }\end{array}$ & $\begin{array}{l}\text { Experimental } \\
\text { Test }\end{array}$ \\
\hline DOF & & & & & & \\
\hline Mode & & & & & & \\
\hline 1 & & & & & & \\
\hline 2 & & & & & & \\
\hline 3 & & & & & & \\
\hline 4 & & & & & & \\
\hline 5 & & & & & & \\
\hline 6 & & & & & & \\
\hline
\end{tabular}

\section{Assessment of the laboratories}

Written reports will be used to evaluate students, as well as the quality outcome of their practical work. One report is required per student. To ensure teaching success, it is important that students present their results in writing in an organized way together with comments and observations. Conclusions will also be used to analyze if students grasped the main concepts of the laboratories. The content of each report and grade percentage was
a) Introduction
$15 \%$
b) Procedure $25 \%$
c) Results $\quad 30 \%$
d) Conclusions $\quad 30 \%$

The following ABET outcomes are taking into account to evaluate students:
(a) an ability to apply knowledge of mathematics, science, and engineering
(b) an ability to design and conduct experiments, as well as to analyze and interpret data
(e) an ability to identify, formulate, and solve engineering problems
(k). an ability to use the techniques, skills, and modern engineering tools necessary for 
engineering practice

The rubric used to assess the work of the students is given in Table 2 .

Table 2. Rubric of the hands-on components of the course.

\begin{tabular}{|c|c|c|c|}
\hline Component & Sophisticated & Competent & Not yet Competent \\
\hline Matlab code RRM & \multirow[t]{2}{*}{$\begin{array}{l}\text { Code is right. Comments } \\
\text { explain each step. }\end{array}$} & \multirow{2}{*}{$\begin{array}{l}\text { Either frequencies } \\
\text { or modes are wrong. }\end{array}$} & \multirow{2}{*}{$\begin{array}{l}\text { Code is wrong. } \\
\text { Frequencies and } \\
\text { modes are plotted } \\
\text { incorrectly. }\end{array}$} \\
\hline Matlab FEM code & & & \\
\hline $\begin{array}{c}\text { Abaqus beam } \\
\text { elements }\end{array}$ & \multirow{3}{*}{$\begin{array}{c}\text { Simulation is set up } \\
\text { correctly. } \\
\text { Modes obtained in Matlab } \\
\text { are properly identified. }\end{array}$} & \multirow{3}{*}{$\begin{array}{c}\text { Either frequencies or } \\
\text { modes are wrong due to } \\
\text { wrong boundary } \\
\text { conditions or material } \\
\text { properties. }\end{array}$} & \multirow{3}{*}{\begin{tabular}{|c|} 
Frequencies or \\
modes are wrong. \\
Modes obtained in \\
Matlab are not \\
properly identified. \\
Student unable to \\
check boundary \\
conditions were not \\
satisfied.
\end{tabular}} \\
\hline $\begin{array}{l}\text { Abaqus shell } \\
\text { elements }\end{array}$ & & & \\
\hline $\begin{array}{c}\text { Abaqus solid } \\
\text { elements }\end{array}$ & & & \\
\hline $\begin{array}{l}\text { Experimental } \\
\text { Work }\end{array}$ & $\begin{array}{l}\text { Experimental work is } \\
\text { properly described. } \\
\text { Results are correct. }\end{array}$ & $\begin{array}{l}\text { Experimental work isn’t } \\
\text { properly described or } \\
\text { results are incorrect. }\end{array}$ & $\begin{array}{c}\text { Both experimental } \\
\text { work is not properly } \\
\text { described and results } \\
\text { are incorrect. }\end{array}$ \\
\hline Conclusions & $\begin{array}{l}\text { All results match. } \\
\text { Convergence with respect } \\
\text { to the increment in the } \\
\text { number of DOF was } \\
\text { identified. Describe } \\
\text { advantages and } \\
\text { disadvantages of the } \\
\text { different elements and } \\
\text { methods. }\end{array}$ & $\begin{array}{c}\text { Some information is } \\
\text { missing. Results have a } \\
\text { larger error than expected. }\end{array}$ & $\begin{array}{l}\text { Conclusions are } \\
\text { vague. } \\
\text { Student doesn't } \\
\text { reflect understanding } \\
\text { of the topics covered } \\
\text { in the labs. }\end{array}$ \\
\hline
\end{tabular}

\section{Comments and Conclusions}

Through these labs it is ensured that students know the basics of beam theory, the FEM, vibratory motion, the generalized eigenvalue problem and most importantly that students gain experience and confidence to implement finite element analysis which lead to accurate results. Results show that students enjoy working with commercial FEM codes. This is shown with clearly higher lab reports' grades -usually higher than $90 \%$, while the average of exams' grades were around $75 \%$ with a standard deviation around $15 \%$. Although the structure is very simple it 
is easy to change the length of the beam to have different results every semester. Furthermore, masses can be added to the beam, which will change the natural frequencies of the beam. The idea of refining meshes also means that meshes are most likely different and will produce slightly different results.

\section{Survey}

In a survey at the start of the semester $85 \%$ students believed that three-dimensional elements produce always better results. At the end of the semester students had a better understanding of the advantages and disadvantages of each type of element.

\section{Students comments}

Students comments included the order of element used with the number of degrees of freedom needed to obtain converged results for each type of elements (beam, shell and solid), as well as comments about the advantages and disadvantages of the elements.

\section{References}

[1] Sullivan, R.W. Integration of Modal Test Results of a Composite Wing into the Introductory Aerospace Vibrations Course, 2016 ASEE Annual Conference \& Exposition, June 26, 2016, ISBN 978-0-692-68565-5.

[2] Tito-Izquierdo, J., Gomez-Rivas, Feng, W. Pincus, G. An Experiment Based Structural Dynamics Course For Engineering Technology Students, 2006 Annual Conference \& Exposition, June 18, 2006.

[3] Abumahaimed, M., Rencis, J. Mechanics of Materials, Machine Design, and Vibrations Finite Element Learning Modules for Undergraduate Courses, Proceedings of the 2011 Midwest Section Conference of the American Society for Engineering Education.

[4] MATLAB Release 2012b, The MathWorks, Inc., Natick, Massachusetts, United States.

[5] Abaqus Scripting User's Manual (6.10).

[6] http://www.abet.org/eac-criteria-2014-2015/.

[7] Author's publication.

Appendix A

format short $\mathrm{g}$

clear

clc

$\% \% \% \% \% \% \% \% \% \% \% \% \% \% \% \% \% \% \% \% \% \% \% \% \% \% \% \% \% \% \% \% \% \% \% \% \% \% \% \%$

$\% \quad$ DIMENSIONALIZED BEAMS

$\% \% \% \% \% \% \% \% \% \% \% \% \% \% \% \% \% \% \% \% \% \% \% \% \% \% \% \% \% \% \% \% \% \% \% \% \% \% \% \% \% \% \% \% \% \%$

$\%$ Number of terms

$n \max =200$;

$\%$ Defining the type of Penalty Parameter

$\mathrm{cM}=0 ; \%$ Inertial Penalty Parameter

$\mathrm{cK}=1 ; \%$ Stiffness type Penalty Parameter 
\% Penalty Parameter Value

PenaltyParameter=1e10;

$\% \% \% \% \% \% \% \% \% \% \% \% \% \% \% \% \% \% \% \% \% \% \% \% \% \% \% \% \% \% \% \% \% \% \% \% \% \% \% \%$

$\% \quad$ DEFINING A BEAM FROM $\mathrm{x}=0$ to $\mathrm{x}=\mathrm{L}$

$\% \% \% \% \% \% \% \% \% \% \% \% \% \% \% \% \% \% \% \% \% \% \% \% \% \% \% \% \% \% \% \% \% \% \% \% \% \% \% \% \%$

$\%$ Defining Material Properties

$\mathrm{E}=2 \mathrm{e} 11 ; \quad \%[\mathrm{~Pa}]$

density $=7800 ; \%\left[\mathrm{~kg} / \mathrm{m}^{\wedge} 3\right]$

$\%$ Defining Geometric Properties

$\mathrm{L}=2 ; \%[\mathrm{~m}]$ Length of the beam

$\mathrm{r}=0.01 ; \%[\mathrm{~m}]$ Radius of the beam

$\%$ Getting some properties of the beam

$\mathrm{I}=\mathrm{pi}^{*} \mathrm{r}^{\wedge} 4 / 4 ; \%\left[\mathrm{~m}^{\wedge} 4\right]$ Second moment of area

$\mathrm{A}=\mathrm{pi}^{*} \mathrm{r}^{\wedge} 2 ; \%\left[\mathrm{~m}^{\wedge} 2\right]$ Area

$\mathrm{m}=$ density*A; \% $[\mathrm{kg} / \mathrm{m}]$ Mass per unit length

$\%$ Defining Boundary Conditions

$\mathrm{k} 1=$ PenaltyParameter $* 1 ; \%$ Translation at $\mathrm{x}=0$

$\mathrm{k} 2=$ PenaltyParameter $* 1 ; \%$ Rotation at $\mathrm{x}=0$

$\mathrm{k} 3=$ PenaltyParameter* $0 ; \%$ Translation at $\mathrm{x}=1$

$\mathrm{k} 4=$ PenaltyParameter $*$; \% Rotation at $\mathrm{x}=1$

$\%$ Getting the Mass and Stiffness matrix of the beam

$[\mathrm{K}, \mathrm{M}]=\operatorname{EigKMBeams}(\mathrm{nmax}, \mathrm{k} 1, \mathrm{k} 2, \mathrm{k} 3, \mathrm{k} 4, \mathrm{cM}, \mathrm{cK})$;

$\mathrm{K}=\mathrm{K}^{*} \mathrm{E}^{*} \mathrm{I} / \mathrm{L}^{\wedge} 3$;

$\mathrm{M}=\mathrm{M} * \mathrm{~m} * \mathrm{~L}$

$\% \% \% \% \% \% \% \% \% \% \% \% \% \% \% \% \% \% \% \% \% \% \% \% \% \% \% \% \% \% \% \% \% \% \% \% \% \% \%$ $\% \quad$ SOLVING THE EIGENVALUE PROBLEM

$\% \% \% \% \% \% \% \% \% \% \% \% \% \% \% \% \% \% \% \% \% \% \% \% \% \% \% \% \% \% \% \% \% \% \% \% \% \% \%$ [X2,Eigenvalues]= eig $(\mathrm{K}, \mathrm{M})$;

Natural_Frequencies_Hz=sqrt(diag(Eigenvalues $)) *(1 /(2 *$ pi $))$

function $[\mathrm{K}, \mathrm{M}]=\operatorname{EigKMBeams}(\mathrm{nmax}, \mathrm{k} 1, \mathrm{k} 2, \mathrm{k} 3, \mathrm{k} 4, \mathrm{cM}, \mathrm{cK})$

$\% \% \% \% \% \% \% \% \% \% \% \% \% \% \% \% \% \% \% \% \% \% \% \% \% \% \% \% \% \% \% \% \% \% \% \% \% \% \% \%$ $\%$ Stiffness Matrix of a beam

\%\%\%\%\%\%\%\%\%\%\%\%\%\%\%\%\%\%\%\%\%\%\%\%\%\%\%\%\%\%\%\%\%\%\%\%\%\%\%\%\%\%\%\%\%\%

$\mathrm{K}(3,3)=4$;

for $\mathrm{i}=4$ : $\mathrm{nmax}$

$\mathrm{K}(\mathrm{i}, \mathrm{i})=0.5^{*} \mathrm{pi}^{\wedge} 4 *(\mathrm{i}-3)^{\wedge} 4$

end 
\%\%\%\%\%\%\%\%\%\%\%\%\%\%\%\%\%\%\%\%\%\%\%\%\%\%\%\%\%\%\%\%\%\%\%\%\%\%\%\%\%\%\%\%\% Adding springs or masses

$\% \% \% \% \% \% \% \% \% \% \% \% \% \% \% \% \% \% \% \% \% \% \% \% \% \% \% \% \% \% \% \% \% \% \% \% \% \% \% \%$ $\%$ TRANSLATIONAL SPRING AT X=0

$\operatorname{Kk} 1(1,1)=1$;

for $\mathrm{i}=4$ :nmax

$\operatorname{Kk} 1(1, \mathrm{i})=1$;

$\operatorname{Kk} 1(\mathrm{i}, 1)=1$;

end

for $\mathrm{i}=4$ :nmax

for $\mathrm{j}=4$ :nmax

$\operatorname{Kk} 1(\mathrm{i}, \mathrm{j})=1$;

end

end

\% ROTATIONAL SPRING AT X=0

$\mathrm{Kk} 2=$ zeros(nmax);

$\operatorname{Kk} 2(2,2)=1$;

$\%$ TRANSLATIONAL SPRING AT X=1

$\mathrm{Kk} 3=$ ones(3);

for $\mathrm{i}=4$ : $\mathrm{nmax}$

$\mathrm{Kk} 3(1, \mathrm{i})=\cos ((\mathrm{i}-3) * \mathrm{pi})$;

$\mathrm{Kk} 3(\mathrm{i}, 1)=\cos ((\mathrm{i}-3) * \mathrm{pi})$;

$\operatorname{Kk} 3(2, \mathrm{i})=\cos ((\mathrm{i}-3) * \mathrm{pi})$;

$\mathrm{Kk} 3(\mathrm{i}, 2)=\cos ((\mathrm{i}-3) * \mathrm{pi})$;

$\operatorname{Kk} 3(3, \mathrm{i})=\cos ((\mathrm{i}-3) * \mathrm{pi})$;

$\mathrm{Kk} 3(\mathrm{i}, 3)=\cos ((\mathrm{i}-3) * \mathrm{pi})$;

end

for $\mathrm{i}=4$ :nmax

for $\mathrm{j}=4$ :nmax

$\operatorname{Kk} 3(\mathrm{i}, \mathrm{j})=\cos ((\mathrm{i}-3) * \mathrm{pi}) * \cos ((\mathrm{j}-3) * \mathrm{pi})$;

end

end

\% ROTATIONAL SPRING AT X=1

$\operatorname{Kk} 4(2,2)=1$;

$\operatorname{Kk} 4(2,3)=2$;

$\operatorname{Kk} 4(3,2)=2$;

$\mathrm{Kk} 4(3,3)=4$;

$\mathrm{Kk} 4(\mathrm{nmax}, \mathrm{nmax})=0$;

$\mathrm{K}=\mathrm{K}+(\mathrm{k} 1 * \mathrm{Kk} 1+\mathrm{k} 2 * \mathrm{Kk} 2+\mathrm{k} 3 * \mathrm{Kk} 3+\mathrm{k} 4 * \mathrm{Kk} 4) * \mathrm{cK}$; 
$\% \% \% \% \% \% \% \% \% \% \% \% \% \% \% \% \% \% \% \% \% \% \% \% \% \% \% \% \% \% \% \% \% \% \% \% \% \% \% \%$ $\% \quad$ MASS MATRIX OF A BEAM

$\% \% \% \% \% \% \% \% \% \% \% \% \% \% \% \% \% \% \% \% \% \% \% \% \% \% \% \% \% \% \% \% \% \% \% \% \% \% \% \%$

$\mathrm{M}(1,1)=1$

$\mathrm{M}(1,2)=1 / 2$;

$\mathrm{M}(2,1)=1 / 2$;

$\mathrm{M}(1,3)=1 / 3$;

$\mathrm{M}(2,2)=1 / 3$;

$\mathrm{M}(3,1)=1 / 3$;

$\mathrm{M}(2,3)=1 / 4$

$\mathrm{M}(3,2)=1 / 4$

$\mathrm{M}(3,3)=1 / 5$;

for $\mathrm{i}=4$ : $\mathrm{nmax}$

$\mathrm{M}(2, \mathrm{i})=(\cos ((\mathrm{i}-3) * \mathrm{pi})-1) /\left((\mathrm{i}-3)^{\wedge} 2 * \mathrm{pi}^{\wedge} 2\right) ;$

$\mathrm{M}(\mathrm{i}, 2)=(\cos ((\mathrm{i}-3) * \mathrm{pi})-1) /\left((\mathrm{i}-3)^{\wedge} 2 * \mathrm{pi}^{\wedge} 2\right)$;

end

for $\mathrm{i}=4$ :nmax

$\mathrm{M}(3, \mathrm{i})=2 * \cos ((\mathrm{i}-3) * \mathrm{pi}) /\left((\mathrm{i}-3)^{\wedge} 2 * \mathrm{pi}^{\wedge} 2\right) ;$

$\mathrm{M}(\mathrm{i}, 3)=2 * \cos \left((\mathrm{i}-3)^{*} \mathrm{pi}\right) /\left((\mathrm{i}-3)^{\wedge} 2 * \mathrm{pi}^{\wedge} 2\right)$;

end

for $\mathrm{i}=4$ :nmax

$\mathrm{M}(\mathrm{i}, \mathrm{i})=1 / 2$;

end

$\mathrm{M}=\mathrm{M}+(\mathrm{k} 1 * \mathrm{Kk} 1+\mathrm{k} 2 * \mathrm{Kk} 2+\mathrm{k} 3 * \mathrm{Kk} 3+\mathrm{k} 4 * \mathrm{Kk} 4) * \mathrm{cM}$ 